\title{
EFFECTS OF GEOMETRIC DETAILS ON SLAT NOISE GENERATION AND PROPAGATION
}

\author{
Mehdi R. Khorrami* and David P. Lockard** \\ NASA Langley Research Center \\ MS 128, Hampton, VA
}

\begin{abstract}
The relevance of geometric details to the generation and propagation of noise from leading-edge slats is considered. Typically, such details are omitted in computational simulations and modelscale experiments thereby creating ambiguities in comparisons with acoustic results from flight tests. The current study uses two-dimensional, computational simulations in conjunction with a Ffowcs Williams-Hawkings (FW-H) solver to investigate the effects of previously neglected slat "bulb" and "blade" seals on the local flow field and the associated acoustic radiation. The computations clearly show that the presence of the "blade" seal at the cusp significantly changes the slat cove flow dynamics, reduces the amplitudes of the radiated sound, and to a lesser extent, alters the directivity beneath the airfoil. Furthermore, it is demonstrated that a modest extension of the baseline "blade" seal further enhances the suppression of slat noise. As a side issue, the utility and equivalence of FW-H methodology for calculating far-field noise as opposed to a more direct approach is examined and demonstrated.
\end{abstract}

\section{Introduction}

During aircraft approach and landing, a significant portion of the airframe noise propagated to the ground is generated by the deployed high-lift system. Minimizing the noise on approach is important for the quality of life of residents living near airports and allow for increased airport capacity. Among the various high-lift components, the leading-edge slat and the side edges of the flaps have been identified as prominent airframe noise sources ${ }^{1-4}$. For practical reasons, mostly model scale experiments have been relied upon to provide insight on sound generation and the radiated acoustic field ${ }^{3,5-7}$. When compared with a full-scale high-lift system, most of the models studied lack certain geometric details that are omitted in order to reduce model manufacturing cost or ease production. Such omissions always create certain ambiguities when directly comparing the acoustic signatures of scaled models and flight tests.

\footnotetext{
*Aerospace Technologist, Computational Aerosciences Branch, Associate Fellow AIAA

**Aerospace Technologist, Computational Aerosciences Branch, Senior Member AIAA
} 
In a 2003 paper, Stoker et al. ${ }^{8}$ presented acoustic array measurements from $6.3 \%, 26 \%$, and full-scale Boeing 777-200 airplanes that were obtained at different facilities. One of the more pronounced differences between the various measurements is the acoustic footprint associated with the leading-edge slat. While the model-scale results depict slat noise to be a prominent source, the flight test data show a much quieter slat. Obviously, there are several possible sources for this discrepancy such as: a) array processing techniques, b) differences in experimental setup and facilities, c) model scale issues, and d) geometric fidelity. It is the latter issue that is the focus of the present paper. As a starting point, we have tried to simulate the effects of two of the omitted seals that are part of a full-size production slat. The two simulated seals are comprised of the "bulb" seal and a "blade" seal. On a real aircraft (Fig. 1), the bulb seal resides on the slat pressure side and prevents full metal contact between the main element surface and the slat underside. The blade seal, which is situated at the slat cusp, provides a seamless surface for the wing's underside when the slat is retracted.

Experimental and computational studies, focused on leading-edge slats, have been instrumental in providing the foundation for an in-depth understanding of noise generation mechanisms and the radiated sound field ${ }^{3,6,7,9-18}$. Following Dobrzynski et al. ${ }^{3}$, compilation of past acoustic measurements ${ }^{3,6,7,9,10}$ reveals a near universal Strouhal $(\mathrm{St})$ scaling, based on the slat chord $\mathrm{C}_{\mathrm{s}}$ and freestream velocity, for the frequency spectrum. Figure 2 depicts a typical, generic slat frequency spectrum for landing conditions. The spectrum is comprised of a low- to mid-frequency broadband component, with a peak at a St frequency in the range of 1-3, followed by a high-frequency tonal component that resides anywhere between $\mathrm{St}=10$ and 50. The high-frequency tonal sound, which can be extremely loud, is caused by shed vortices from the finite-thickness trailing edge ${ }^{11,12}$. Extensive computational simulations ${ }^{13-14,16-18}$ in conjunction with particle image velocimetry measurements ${ }^{15,19}$ of the slat cove flow field have revealed the cause and the effect between the coherent structures of the free-shear layer at the cusp and the lowfrequency broadband component of the acoustic spectrum.

Slat cove cover ${ }^{3}$ and slat cove filler ${ }^{20-21}$ modifications that either delay or altogether remove shear layer formation have been shown to reduce the broadband noise by $3-4 \mathrm{~dB}$. The effectiveness of these noise reduction concepts underscores the importance of the cove flow originating at the cusp and how its alteration may provide substantial noise benefits. The relevance of the shear flow initiating from the cusp has been the motivating factor behind our conjecture that the presence of the blade seal may lower the slat noise signature. Indeed, it may prove to be a plausible explanation for the discrepancies between the model-scale acoustic results and flight test data observed by Stoker ${ }^{8}$. The present effort is an attempt to test this conjecture via computational simulations. The work also highlights that small geometric details may exert too much influence for their effects to be neglected for a particular flow field. 
This research was conducted during the 2003-2004 timeframe as part of a larger effort to understand the underlying physics of slat noise generation.

\section{Computational Procedure}

The present computational framework follows a hybrid approach consisting of a highly resolved two-dimensional (2-D) CFD solution of the local flow unsteadiness (noise sources) which is then used as an input to a FW-H acoustic formulation to obtain the propagated sound field and directivity pattern. The approach was outlined in our previous work, ${ }^{22}$ and, hence, only a brief overview is given below.

\section{$2.1 \quad$ Flow Solver}

The CFL3D code used to compute the flow field solves the compressible, three-dimensional, timedependent, thin-layer Navier-Stokes equations with a finite-volume formulation. In CFL3D, numerous turbulence models are provided, including 0-, 1-, and 2-equation models. Following our previous studies, the 2-equation shear stress transport $(k-\omega)$ model of Menter $^{23}$ was selected as the turbulence model for the present problem. Given the success of our earlier zonal approach ${ }^{13,14}$, the flow in the slat cove region is assumed to be quasi-laminar. Accordingly, the production term associated with the turbulence model is switched off in a limited zone that encloses the cove area. However, in 2-D mode, the quasi-laminar zonal approach produces large-scale vortical structures within the slat cove region that are excessively energetic. This excess energy was shown by Choudhari and Khorrami ${ }^{18}$ to be due to a lack of 3-D effects which prevents the onset of secondary instabilities of the spanwise rollers and thus omits conversion of spanwise vorticity into streamwise vorticity. Nevertheless, we believe the current 2-D computations provide sufficient insight into the effects of a blade seal on the slat cove flow field to forego the more expensive 3-D simulations during this initial investigation.

All current computations are performed using the second-order-accurate time discretization and the “dual-time stepping" method. ${ }^{24}$ Between 25-30 subiterations, in conjunction with 3-level V-type multigrid cycles, are utilized to ensure a minimum of two orders of magnitude drop in both the mean-flow and turbulence-model residuals during each time step.

\subsection{FW-H Solver}

Despite continued advances in computational resources and numerical algorithms, it is still prohibitively expensive and often infeasible to attempt to resolve wave propagation from near-field 
sources to far-field observers. Integral techniques that can predict the far-field signal based solely on near-field input are a means to overcome this difficulty. Hence, the Ffowcs Williams-Hawkings (FW-H) equation $^{25}$ solver described by Lockard ${ }^{26}$ is used to predict the acoustic signature at various observer locations using unsteady flow data from the CFD calculation.

The FW-H equation is an exact rearrangement of the Navier-Stokes equations that allows one to determine the acoustic signal at distant observer locations if the details of the source region are already known. Hence, the Navier-Stokes equations still need to be solved, but only where nonlinear and viscous effects are important. All of the linear propagation can be determined by the FW-H equation. For threedimensional flows, the time-domain FW-H formulations developed by Farassat ${ }^{27}$ are efficient and amenable to numerical computations. Some additional efficiency can be obtained by restricting the source to uniform, rectilinear motion. As an alternative to the time-domain formulation, the FW-H equation can be solved in the frequency domain, which can be useful if one is only interested in analyzing certain frequencies. A frequency domain version of FW-H equation is given in reference 26. The volumetric quadrupole term includes effects such as nonlinear propagation and refraction. In this work, the FW-H integration surface is placed outside of the region with large flow gradients so the volumetric quadrupole contribution should be small and can be neglected.

\subsection{Geometry and Grid}

The geometry under consideration is from a Boeing 777 high-lift system. A sectional profile of the high-lift system in a landing configuration was provided to us by Boeing researchers. To simplify the task of grid generation and the subsequent computations, we have taken the liberty of making the main element and flap trailing edges sharp while maintaining their respective cambers. On the other hand, the finite thickness of the slat trailing edge was maintained for all of our simulations. Figure 3 displays the 2$\mathrm{D}$ profile (along the direction normal to the leading edge of the wing) of the various elements in the simulated landing configuration.

Figure 4 displays an expanded view of the two additional geometric details that have been added to the B777 slat geometry in order to approach the fidelity of a full-scale production slat. The effectiveness of a longer blade seal in suppressing slat noise is also examined. Figure 4 shows in red the extent of our longer blade seal. The blade seal is incorporated into the geometry as a zero thickness solid line on which the no-slip boundary condition is enforced on both interior and exterior sides. The length of the baseline and extended blade seals are approximately $10 \%$ and $25 \%$ of the slat chord, respectively. 
Consistent with the objective behind this work, the computational grid was designed to provide appropriate spatial resolution of the flow field near the slat. The extent of the simulated domain and an expanded view of the grid distribution surrounding the high-lift system are shown in Fig.5. The front, top, and bottom boundaries are placed 11 chords away from the leading edge of the main element while the downstream boundary is 22 chords away. The computational domain surrounding the slat was divided into 24 blocks, with clustered mesh near the solid surfaces, trailing edge, wake, and the cove. The extreme concentration of mesh points in the slat cove area (appearing as a large dark zone in the grid shown in Fig. 3b) is deliberate and was constructed for the purpose of accurately capturing the free shear layer emanating from the slat cusp. The fine resolution maintained beneath the high-lift system (at distances greater than a slat chord) is also intentional. Although unnecessary for resolving any of the potential noise sources, it affords us the ability to compare the results obtained from the FW-H solver directly with those extracted from the CFD solution. The overall 2-D grid contains a total of 1.318 million grid points, with nearly sixty percent of the nodes clustered in the vicinity of the slat.

\section{Results}

The post-processed results are presented as non-dimensional quantities. The nondimensionalization is with respect to the mean aerodynamic chord $\mathrm{C}$ of the stowed wing and the freestream speed of sound, density, and molecular viscosity. For the present case, the reference flow variables are set to match a typical landing condition. The flow conditions for the simulations correspond to $\mathrm{M}=0.2$ and $\mathrm{Re}=10$ million. It is noted that the chosen $\mathrm{Re}$ is a factor of three smaller than the flight Reynolds number. However, previous wind tunnel acoustic measurements have shown that slat noise sources become independent of Re for values greater than 7 million ${ }^{6}$. Thus, we believe that simulating the flow field at $\mathrm{Re}=10$ million has allowed us to accomplish the computations at a much lower cost than the flight Re without sacrificing the acoustic imprint of the leading-edge slat.

A constant nondimensional time step of $\Delta t=2.7484 \times 10^{-4}$ (corresponding to 200 points per period for a $1000 \mathrm{~Hz}$ signal) is used for all simulations. Typically, the simulations are run for 5000-6000 time steps to allow the transient flow field to wash out before collecting or analyzing time records. A typical time-average includes 13000-14000 samples collected every fourth time step. Such a record contains in excess of 25 cycles where each cycle represents the convective time scale sufficient for the flow field to traverse the distance between the slat cusp and the slat trailing edge.

Preliminary scrutiny of the simulated results made it clear that the presence of the bulb seal has a small effect on the slat-cove flow dynamics. Therefore, for the present study, the slat with the bulb seal is 
considered to be the baseline case against which the influence of adding the blade seal is to be judged. All computations are conducted at 6 degrees angle-of-attack to mimic a typical approach condition.

\subsection{Surface Pressure and Global Velocity Field}

From the global perspective and within the accuracy of the current simulations, the addition of the baseline or the extended blade seal to the slat geometry produces no measurable change in the total lift or drag coefficients $\left(C_{L}\right.$ and $\left.C_{D}\right)$. That is, the overall aerodynamic efficiency of the high-lift system remains unaffected. To illustrate the point, the pressure distribution on all three elements for the cases of no blade seal and the extended blade seal are presented in Fig.6. The computed pressure coefficients are virtually identical and depict a typical pressure distribution on a multi-element high-lift system. The pressure distribution over the flap indicates a large-scale flow separation that covers a significant portion of the upper (suction) surface. The overly large extent of the flap separation is mostly attributed to the 2-D nature of the simulations, which curtails the ability of the flow to breathe in the spanwise direction. In addition, the sharpening of the flap trailing edge thickness adds a small but measurable amount of adverse streamwise pressure gradient.

The averaged global velocity (magnitude) color contours for the case without the blade seal are shown in Fig.7. High-speed flow (low pressure) regions, caused by flow acceleration through the gaps, occur near the leading edges of the main element and the flap. Low speed recirculating flow regions are present within the slat and main element coves. As expected, the presence of flap separation produces an additional low speed flow region. The mean streamlines, in the vicinity of the slat for the case of no blade seal, are displayed in Fig. 8. The bulb seal acts as a barrier along the path of the recirculating flow on the slat bottom surface, causing separation of the boundary layer and formation of a dead flow zone in the corner region. Certainly, the dead zone would have been present even without the seal present, but to a much smaller extent. Beyond the cove corner, the flow reattaches to the slat surface before separating again near the slat cusp. Except for a moderate enlargement of the secondary separation zone near the cusp, addition of the baseline or the extended blade seal does not alter the picture of the cove's mean streamlines (Fig.8) and therefore are omitted.

\subsection{Slat Local Flow Field}

In contrast to the global picture, locally, the addition of the blade seal and in particular the extended blade seal has a significant effect on the dynamics of the unsteady flow field within the slat cove. As a prelude to the discussion of the time-dependent flow, it is informative to briefly highlight some of the differences between the mean flow field with and without the blade seal, particularly from the standpoint 
of noise generation. The mean spanwise vorticity distributions for the cases of no blade, baseline blade, and extended blade seal are shown in Figs.9a-c, respectively. In the absence of the seal (Fig. 9a), the flow field displays a very rapid initial growth of the free-shear-layer thickness. This initial rapid thickening is partially due to the immediate roll up of the shear layer into large-scale vortices (rollers) and partially caused by the presence of a spatial jitter in the rollers' positions near the cusp. Beyond this initial stage, the vorticity layer diffuses over a wide spatial band before arriving at the reattachment location. This apparent diffusion of the vorticity layer is caused by the large meandering of the rolled up vortices along their migratory path between the slat cusp and the reattachment location and has less to do with an ordinary viscous diffusion. For the no blade case, the average reattachment point occurs at a distance of $0.095 \mathrm{C}_{\mathrm{s}}$ from the trailing edge, where $\mathrm{C}_{\mathrm{s}}$ is the slat chord. At the reattachment point, a portion of the shear-layer vorticity ends up within the cove recirculating zone depicted as a circular outer band of counterclockwise vorticity (Fig.9a). The thickness of this band indicates that some of the shear layer vortices end up being trapped within the cove flow field providing the necessary ingredients for a feedback loop to be established inside the cove region.

Shear layer development is altered significantly by the placement of the baseline blade seal at the cusp (Fig. 9b). In contrast to the case without the blade seal, the shear layer thickness grows more in line with a typical splitter-plate mixing layer and has a well-defined outline. Moreover, the shear layer maintains high vorticity levels over a longer distance indicating that discrete vortices travel toward the reattachment location within a narrow spatial band. The reattachment point is moved closer to the trailing edge and now resides at a distance of $0.084 \mathrm{C}_{\mathrm{s}}$ from the edge. Once again, part of the shear layer vorticity recirculates in an outer spatial ring of the cove. Extending the length of the blade seal further accentuates those aspects of the cove flow field that were affected with the introduction of the baseline blade seal. Notice that the shear layer has a very well defined path and thickness (Fig. 9c) where most of the vorticity is concentrated. Beyond the initial growth, the shear layer maintains a near constant width all the way up to the reattachment location. The constant thickness is due to the shortened developmental path, leaving little opportunity for the shear layer vortices to interact with each other. As such, the vortices do not meander too far away from the mean flow streamlines. With the extended blade seal, the reattachment location is pushed further out towards the trailing edge, residing $0.072 \mathrm{C}_{\mathrm{s}}$ from the edge. Beyond the reattachment point, the shear layer portion of the counterclockwise oriented vorticity trapped within the cove recirculation zone is mainly confined to a thin layer adjacent to the slat bottom surface and barely survives to make it to the interior of the cove. Figure $9 \mathrm{c}$ also shows that a good part of the shear layer vorticity passes over the slat trailing edge and influences the vortex shedding process that is present at the finite thickness edge. 
Installing a blade seal at the slat cusp has a major impact on the cove flow dynamics and the corresponding noise sources. Sample plots of the instantaneous spanwise vorticity field for the three slat configurations are shown in Fig.10. Without the blade seal, the shear-layer vortices are more energetic and follow a more chaotic path as they migrate towards the reattachment point on the slat pressure surface. At the reattachment point, most of the vortices take an inward path and get trapped inside the recirculation zone. The trapped vortices have excessive longevity mainly due to the lack of 3-D effects ${ }^{18}$. The bulb seal acts as a barrier along the path of the vortices on the slat bottom surface, causing separation and roll-up of the boundary layer into vortices of opposite sign vorticity. As indicated earlier, the bulb seal generates a dead flow zone in the corner region, but in the absence of any close by edges, the noise generation implications of such a zone are rather benign. Interaction of the trapped interior vortices with the separation zone at the cusp produces extra flow unsteadiness that significantly affects the shear layer roll-up process. The interaction also imparts the aforementioned jitter to the vortices that are formed immediately downstream of the cusp point.

In contrast, both the baseline and the extended blade seals provide a shorter fetch of the shear layer region, resulting in a more benign process of pairing and merging of the vortices. The presence of the blade seal introduces flow characteristics that are typical of splitter-plate mixing layers. That is, amplification of convective instabilities resulting in a chain of rollers followed by nonlinear interactions and vortex pairing. In fact, in the case of the extended blade seal, the shear layer remains intact over most of the distance between the blade trailing edge and the reattachment point before the roll-up process begins and discrete vortices are formed (Fig. 10c). With the addition of the blade seal, most of the rollers still end up inside the recirculation zone. However, there seems to be less overall activity in the center of the cove region compared to the case without the seal.

A more revealing picture of the cove noise sources and their strengths is obtained via examination of the instantaneous density field. The corresponding dilatation fields for the three simulated slat cases are shown in Fig.11. A detailed discussion on the connection between the dilatation field and the noise sources is provided by Lilley ${ }^{28}$ and not repeated here. Notice that in the absence of a blade seal, the shear layer vortices emanating from the slat cusp produce significant variations in the rate of dilatation within the cove region. The rollers' footprints on the dilatation field remain visible over long distances reaching the reattachment point and the slat trailing edge. With the baseline blade seal, the most prominent changes in the density field are confined to a region near the tip of the blade seal, but, farther downstream, the shear layer vortices leave less of an imprint compared to the case without the blade seal. The extended seal eliminates most of the smaller scale vortices, further diminishes the variation in the density field, and, consequently, reduces the strength of the noise sources. We draw upon the stability characteristics of free 
shear layers to help explain the cause of this dramatic change in the formation and subsequent behavior of the rollers. For the case without the blade, scrutiny of the computed solutions reveals that the free shear layer near its detachment point is extremely thin (high shear concentration) and possesses a one-sided velocity profile. Scaling with the shear layer local thickness and velocity gradient, the amplified disturbances are short wave instabilities possessing large growth rates. Beyond the nonlinear amplification and shear layer roll up process, the instabilities manifest themselves as strong, small-scale vortices with significant density (pressure) and velocity gradients inside their cores. Placement of the blade seal at the cusp alters important shear layer parameters, including its thickness and the velocity difference across the layer. By introducing a second stream on the interior side, the blade enlarges the shear layer thickness and reduces the velocity difference. Both trends help lower the amplification rate and the wavenumber of the amplified disturbances. Therefore, the rolled-up vortices are generally larger in size and weaker in strength (Fig. 11b). Extension of the blade seal accentuates the shear layer alterations, resulting in further changes in the thickness and velocity difference. Accordingly, the generated vortices are even larger in size and much more diffused than those associated with the flow field without the blade seal (Fig. 11c).

The computations revealed the presence of two other sources of flow unsteadiness for the 777 highlift system that are worth mentioning. Returning to figures 10 and 11, notice that the plots indicate the presence of slat trailing-edge vortex shedding which turns out to be another prominent noise source. The second source of unsteadiness is the separated zone over the flap which produces regular but very low frequency flow oscillations via shedding from the flap trailing edge. The flap wake oscillations, although not the primary target of the present study, do create certain ambiguities when slat far-field noise is sought. We will return to this point in the following section.

\subsection{Computed Far Field Noise}

Unsteady flow data on a permeable surface enclosing the wing elements and the slat-cove region is used as input to the code described by Lockard ${ }^{26}$ to calculate the noise radiated around the airfoil using the Ffowcs Williams and Hawkings ${ }^{25}$ equation. The geometry and surface are shown in figure 12. Computations using solid-surface data were also performed but are not presented here because of discrepancies caused by apparent quadrupole contributions in the cove region as discussed by Casper et $\mathrm{al}^{29}$.

Figure 13 shows the directivity patterns of the slat noise for the configurations that were considered. The observers are located on a circle with a radius of 10 chords. The directivity patterns 
depict a dipole source behavior for the noise oscillating in a direction that is nearly normal to the slat chord. The directivity angle is measured from the downstream direction and increases in the counterclockwise direction. The present results agree with those from recent simulations by Choudhari and Khorrami ${ }^{18}$, conducted for a generic high-lift configuration, and lend much support to the Dobrzynski and Pott-Pollenske ${ }^{10}$ acoustic dipole model of slat noise source.

The addition of the blade seal produces a measurable impact on both the broadband and the tonal components of the slat's acoustic signature, significantly diminishing the amplitude of the radiated sound associated with each component. The most pronounced effects occur at an angle of 298 degrees that is aft of the overhead direction and corresponds to the downward direction along which highest noise levels are observed. Extending the blade seal further reduces the noise along this direction and, to a lesser extent, alters the directivity pattern. For reasons not fully understood, the addition of the blade seal somewhat increases the magnitude of the flap wake oscillations, despite the fact that in the averaged sense, the total circulation (lift) around each element of the high-lift system remains unchanged. To exclude the flap noise and isolate the slat radiation, the low frequency (sub $50 \mathrm{~Hz}$ ) fluctuations were filtered out from all the presented acoustic results.

The acoustic spectra, computed in 1/3 octave bands at an observer location 10 chords away, are plotted in Fig. 14. Results for 270 degrees (overhead) and 298 degrees (maximum pressure) are provided. The curves display both the broadband (low to mid frequency) and the tonal (high frequency) components that are prominent in a typical slat spectrum (Fig. 2). With or without the blade seal, all three spectra peak at frequencies near $150 \mathrm{~Hz}$. Using the slat chord $\mathrm{C}_{\mathrm{s}}$, the corresponding Strouhal frequency of 1.5 is in good agreement with the universal curve of Fig. 2. The tonal peak between $3 \mathrm{kHz}$ and $4 \mathrm{kHz}$ is caused by shed vortices at the slat trailing edge. The presence of the baseline blade seal reduces the pressure levels 2-4 $\mathrm{dB}$ in the lower frequency range and even more at higher frequencies, providing evidence that geometric fidelity may be partially responsible for the observed differences in spectra from model experiments and flight tests ${ }^{8}$. The larger blade provides an additional 2-3 dB relief for the low-frequency broadband component of slat noise and significantly diminishes the tonal component. Moreover, it shifts the tonal peak to a much higher frequency. The alteration of the high-frequency tonal noise is best illustrated by the perturbation density field plotted in Fig. 15. Notice that on the scale shown, the extended blade seal virtually eliminates the propagating shortwave disturbances that emanate from the leading-edge slat.

To explain the cause of this reduction in tonal noise and the shift to higher frequencies, we discuss the local flow field in the slat trailing-edge region (Fig. 16). As pointed out in previous sections, for the 
case without the blade seal, the shear layer reattachment point is at its farthest distance from the trailing edge. The shear layer's exterior velocity field has more time to align itself with the slat bottom surface and, therefore, leaves the gap region less inclined to the trailing edge. The resulting local flow field at the trailing edge is wake like and absolutely unstable, allowing conventional vortex shedding process to be established. However, due to rapid acceleration of the gap flow and its inherent inclination to the slat contour near the trailing edge, the prominent vortices mostly rotate counterclockwise. The close proximity of the rolled-up vortices to the edge generates large pressure fluctuations at the corners ${ }^{11}$ which are then scattered as high amplitude acoustic waves. It should be observed that the shed vortices scale with the trailing-edge height. With the extended blade seal, the shear layer reattachment point is pushed closer to the slat trailing edge causing the gap flow adjacent to the bottom surface to be more upwardly inclined to the edge. Scrutiny of the flow field downstream of the trailing edge reveals a wake profile that possesses extremely high velocity gradients on its lower side but small velocity gradients on the upper side. Therefore, rather than supporting absolute instabilities, the resulting edge flow field is now convectively unstable. Accordingly, the roll up process takes place farther downstream of the edge and the resulting vortices are weaker in nature. We also note that the vortices now scale with the detached boundary layer thickness rather than the trailing edge height and operate at higher frequencies. Correspondingly, the generated pressure signals are at higher frequencies but lower amplitudes which explain the difference in tonal noise behavior between the extended blade and the no blade seal results displayed in figures 14 and 15.

\section{$3.4 \quad$ FW-H vs. CFD Comparison}

Although FW-H codes have proven to be viable for many aeroacoustic problems, there is danger in viewing them as black boxes. Depending on the flow field under consideration, selecting the integration surface locations, the appropriateness of neglecting the quadrupole terms, and the fidelity of input data require careful consideration. In order to gauge the validity of the formulation and the accompanying assumptions, a direct comparison between acoustic analogy output and those obtained from a CFD simulation can be performed. As described in an earlier section, the high grid resolution achieved underneath the high-lift system, while unnecessary to simulate the noise sources or to apply the FW-H equation, was maintained with this intention in mind.

For comparison purposes, five distinct locations of successively increasing distance from the slat were selected to probe the CFD results and extract the unsteady pressure data. The spatial locations of probes 1-4 are displayed relative to the high-lift system solid surfaces and FW-H surface in Fig. 12. The $5^{\text {th }}$ location (not shown) resides directly beneath the $4^{\text {th }}$ probe at a distance of two chords from the main 
element leading edge. Only results for the case without the blade seal are presented. The extracted CFD pressure plus the computed pressure signal obtained from the FW-H solver are plotted in Fig. 17 for all 5 probe stations. The displayed spectra are normalized to $1 \mathrm{~Hz}$ bin widths and can be viewed as spectral density plots. At the first probe location, which is relatively close to the permeable data surface, the two different pressure records are virtually identical. At the second station, the two signals maintain excellent agreement in the low- to mid-frequency range (slat broadband noise component) but the CFD result shows suppression of the high-frequency (tonal noise) component, due to the stretched grid and the low order of accuracy of the flow solver. The CFD records at the two following locations show additional signal degradation at lower frequencies, yet still maintain a degree of resemblance to the FW-H signals. At the last $\left(5^{\text {th }}\right)$ probe location, the CFD pressure signal has lost most of its frequency content and bears little resemblance to the spectrum obtained from the acoustic formulation. This near total loss of the CFD signal is expected due to the presence of a patch interface between the $4^{\text {th }}$ and $5^{\text {th }}$ probe stations where the grid coarsens significantly.

The comparison is quite reassuring and reaffirms the notion that, given a judicious placement of the permeable surface, FW-H calculations produce results that are equivalent to the more direct but costlier computational approaches. Figures $17 \mathrm{a}$ and $17 \mathrm{~b}$ provide ample evidence of the ability of the acoustic propagation code to reconstruct the convected pressure signal without introducing amplitude or phase distortion. However, the FW-H results are only as good as the input data. Hence, the underlying, central question is how to best simulate the near-field flow where noise generation takes place.

\section{Conclusions}

The influence of two slat geometric details on the local flow field and radiated noise has been studied using two-dimensional, zonal URANS simulations and Ffowcs Williams-Hawkings calculations. A Boeing 777 high-lift system was used for the study. The simulations showed that a "bulb" seal contributes to a dead zone in the slate cove, but does not appear to have any significant influence on global flow characteristics or noise generation. However, the addition of a "blade" seal to the slat cusp alters the shear layer characteristics, reducing the strength of the vortices growing in the layer. Furthermore, the migratory path of the vortices is confined to a narrower band, and the reattachment point is moved closer to the trailing edge. Calculations with an extended blade seal revealed further weakening of the shear layer vortices. The longer blade seal also altered the wake instability behavior at the slat trailing edge, resulting in much weaker shed vortices. The noise calculations demonstrated that the addition of the blade seal significantly reduces the radiated noise in a manner consistent with the changes 
in the local flow field. The extended blade seal provided additional noise benefits at the lower frequencies, and significantly diminished the high-frequency tonal sound.

Comparisons between the noise calculations and direct CFD results were used to demonstrate the suitability of the hybrid approach. Although the overall findings on the impact of the blade seal are consistent with observed differences between model scale experiments and flight measurements, further validation is needed. The present two-dimensional simulations employ a profile from a certain spanwise location, and the geometric details, including those of the seals, change in the spanwise direction. Furthermore, three-dimensional effects are known to have a strong impact on the development of the

coherent structures in the cove region. Nonetheless, the current simulations suggest that previously ignored geometric details can have unexpectedly important influences on the unsteady features of highlift flow fields. Similar unexpected changes may be present on other configurations such as flap edges, but possibly complex interactions between the geometric details and the flow require each case to be evaluated separately. Further study and experiments are needed to confirm whether these kinds of details are responsible for the discrepancies between model and full-scale slat measurements.

\section{Acknowledgment}

The authors would like to express their appreciation to Mr. M.R. Wiese of the Analytical Services and Materials, Inc. for generating the grid used during the computations and Dr. Robert Stoker of the Boeing Company for providing the high-lift profile and the dimensions of the various seals.

\section{References}

1. Meadows, K. R., Brooks, T. F., Humphreys, W. M., Hunter, W. H., and Gerhold, C. H., “Aeroacoustic Measurements of a Wing-Flap Configuration,” AIAA Paper 97-1595, 1997.

2. Hayes, J. A., Horne, W. C., Soderman, P. T., and Bent, P. H., "Airframe Noise Characteristics of a 4.7\% Scale DC-10 Model," AIAA Paper 97-1594, 1997.

3. Dobrzynski, W., Nagakura, K., Gehlhar, B., and Buschbaum, A., "Airframe Noise Studies on Wings with Deployed High-Lift Devices,” AIAA Paper 98-2337, 1998.

4. Davy, R. and Remy, H., "Airframe Noise Characteristics on a 1/11 Scale Airbus Model," AIAA Paper 98-2335, 1998. 
5. Storms, B.L., Ross, J.C., Horne, W.C., Hayes, J.A., Dougherty, R.P., Underbrink, J.R., Scharpf, D.F., and Moriarty, P.J., “An Aeroacoustic Study of an Unswept Wing with a Three-Dimensional High Lift System,”NASA TM 112222, Feb. 1998.

6. Choudhari, M. M., Lockard, D. P., Macaraeg, M. G., Singer, B. A., Streett, C. L., Neubert, G. R., Stoker, R. W., Underbrink, J. R., Berkman, M. E., Khorrami, M. R. and Sadowski, S. S., “Aeroacoustic Experiments in the Langley Low-Turbulence Pressure Tunnel," NASA TM 211432, 2002.

7. Mendoza, J.F., Brooks, T.F., and Humphreys, W.M., Jr., "Aeroacoustic Measurements of a Wing/Slat Model," AIAA Paper 2002-2604, June 2002.

8. Stoker, R.W., Guo, Y., Streett, C., and Burnside, N., "Airframe Noise Source Locations of a 777 Aircraft in Flight and Comparisons with Past Model Scale Tests," AIAA Paper 2003-3232, May 2003.

9. Storms, B.L., Hayes, J.A., Moriarty, P.J., and Ross, J.C., "Aeroacoustic Measurements of Slat Noise on a Three-Dimensional High-Lift System,” AIAA Paper 99-1957, May 1999.

10. Dobrzynski, W. and Pott-Pollenske, M., "Slat Noise Source Studies for Farfield Noise Prediction," AIAA Paper 2001-2158, May 2001.

11. Khorrami, M.R., Berkman, M.E., and Choudhari, M., "Unsteady Flow Computations of a Slat with a Blunt Trailing Edge,” AIAA J., Vol. 38, No. 11, November, pp. 2050-2058, 2000.

12. Singer, B.A., Lockard, D.P., and Brentner, K.S., "Computational Aeroacoustic Analysis of Slat Trailing-Edge Flow,” AIAA J. Vol. 38, No. 9, September, pp. 1558-1564, 2000.

13. Khorrami, M.R., Singer, B. A., and Lockard, D.P., "Time-Accurate Simulations and Acoustic Analysis of Slat Free-Shear-Layer: Part II,” AIAA Paper 2002-2579, 2002.

14. Choudhari, M., Khorrami, M.R., Lockard, D.P., Atkins, H., and Lilley, G., "Slat Cove Noise Modeling: A Posteriori Analysis of Unsteady RANS Simulations," AIAA Paper 2002-2468, 2002.

15. Jenkins, L.N., Khorrami, M.R., Choudhari, M., "Characterization of Unsteady Flow Structures Near Leading-Edge Slat: Part I. PIV Measurements,” AIAA Paper 2004-2801, 2004. 
16. Khorrami, M.R., Choudhari, M., and Jenkins, L.N., "Characterization of Unsteady Flow Structures Near Leading-Edge Slat: Part II. 2D Computations,” AIAA Paper 2004-2802, 2004.

17. Deck, S., "Zonal-Detached-Eddy Simulation of the Flow Around a High-Lift Configuration," AIAA J., Vol., No.11, pp. 2372-2384, Nov. 2005.

18. Choudhari, M.M. and Khorrami, M.R., "Slat Cove Unsteadiness: Effect of 3D Flow Structures," AIAA Paper 2006-0211, January 2006.

19. Takeda, K. Ashcroft, G.B, and Zhang, X., "Unsteady Aerodynamics of Slat Cove Flow in a High-Lift Device Configuration,” AIAA Paper 2001-0706, January 2001.

20. Horne, W. C., James, K.D., Arledge, T.K., Soderman, P.T., Burnside, N., and Jaeger, S.M., "Measurements of 26\%-scale 777 Airframe Noise in the NASA Ames 40- by 80 Foot Wind Tunnel," AIAA Paper 2005-2810, May 2005.

21. Streett, C.L., Casper, J.H., Lockard, D.P., Khorrami, M.R., Stoker, R.W., Elkoby, R., Wenneman, W.F., and Underbrink, J.R., “Aerodynamic Noise Reduction for High-Lift Devices on a swept Wing model," AIAA Paper 2006-212, January 2006.

22. Singer, B. A., Lockard, D. P. and Lilley, G. M., "Hybrid Acoustic Predictions," Computers \& Mathematics with Applications, 46(4), pp. 647-670, August, 2003.

23. Menter, F., "Improved Two-Equation k- $\omega$ Turbulence Models for Aerodynamic Flows," NASA TM $103975,1992$.

24. Rumsey, C. L., Sanetrik, M. D., Biedron, R. T., Melson, N. D., and Parlette, E. B., "Efficiency and Accuracy of Time-Accurate Turbulent Navier-Stokes Computations," Computers \& Fluids, Vol. 25, No. 2, pp. 217-236, 1996.

25. Ffowcs Williams, J. E. and Hawkings, D. L., "Sound Generation by Turbulence and Surfaces in Arbitrary Motion," Philosophical Transactions of the Royal Society of London A, Vol. 342, 1969, pp. 264-321.

26. Lockard, D. P., "An Efficient, Two-Dimensional Implementation of the Ffowcs Williams and Hawkings Equation," J. of Sound and Vibration, Vol. 229, No. 4, 2000, pp. 897-911.

27. Farassat, F., "Linear Acoustic Formulas for Calculation of Rotating Blade Noise," AIAA J., Vol. 19, No. 9, 1981, pp. 1122-1120. 
28. Lilley, G.M., "Radiated Noise from Isotropic Turbulence with Applications to the Theory of Jet Noise," J. Sound and Vibration, Vol. 190, No. 3, pp. 463-476, February 1996.

29. Casper, J. H., Lockard, D. P., Khorrami, M. R. and Streett, C. L., "Investigation of Volumetric Sources in Airframe Noise Simulations,” AIAA Paper 2004-2805, May 2004. 


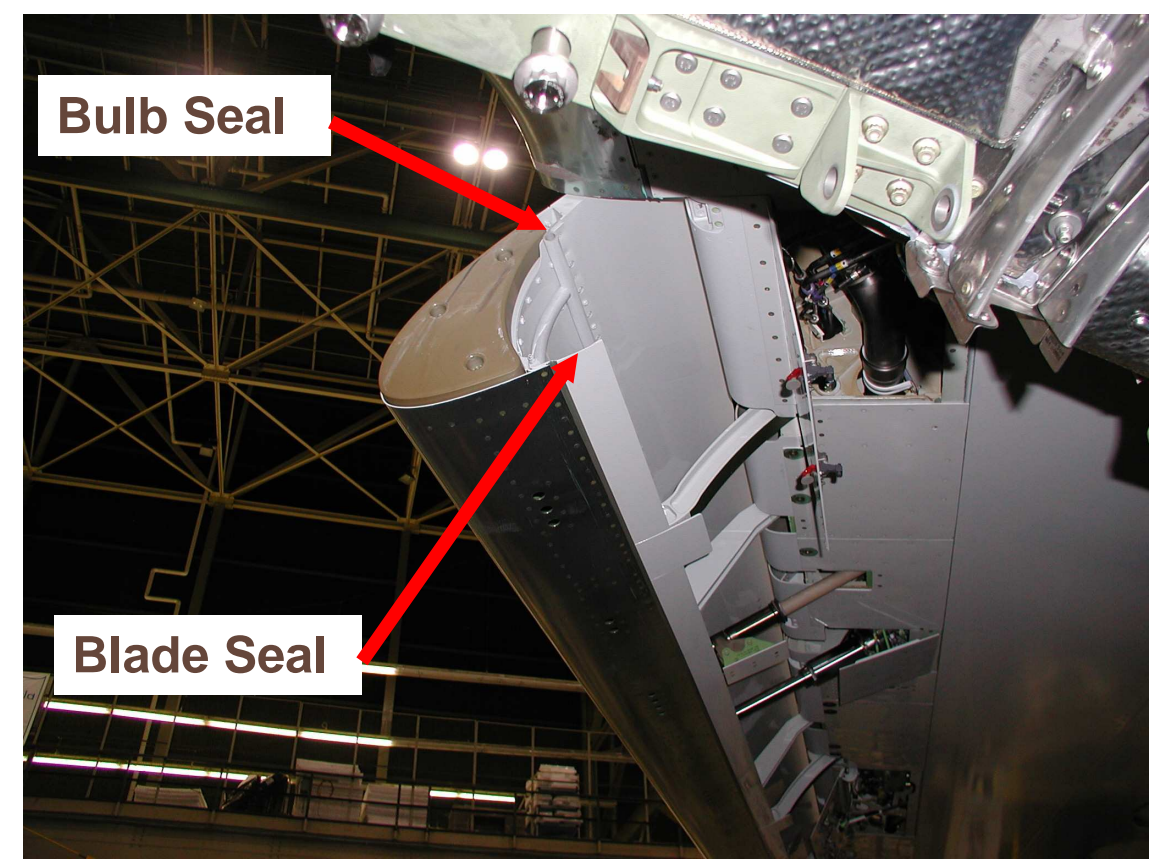

Fig.1. Photo of Boeing 777 slat illustrating presence of "bulb" and "blade" seals

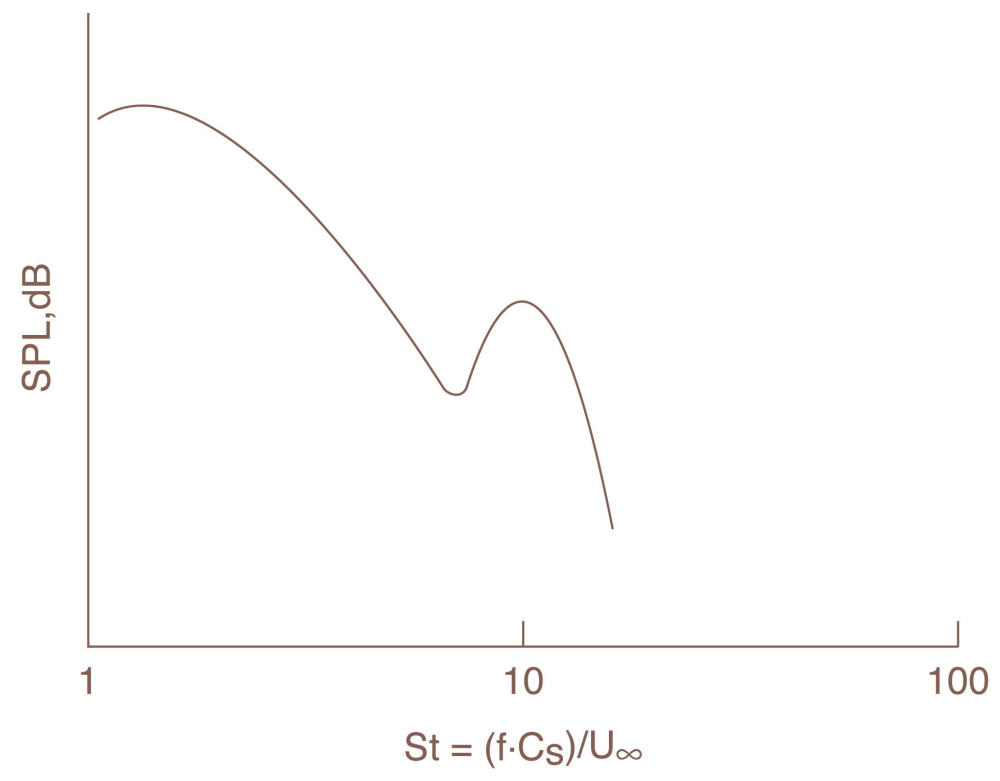

Fig.2. A generic slat acoustic spectrum based on Strouhal frequency 


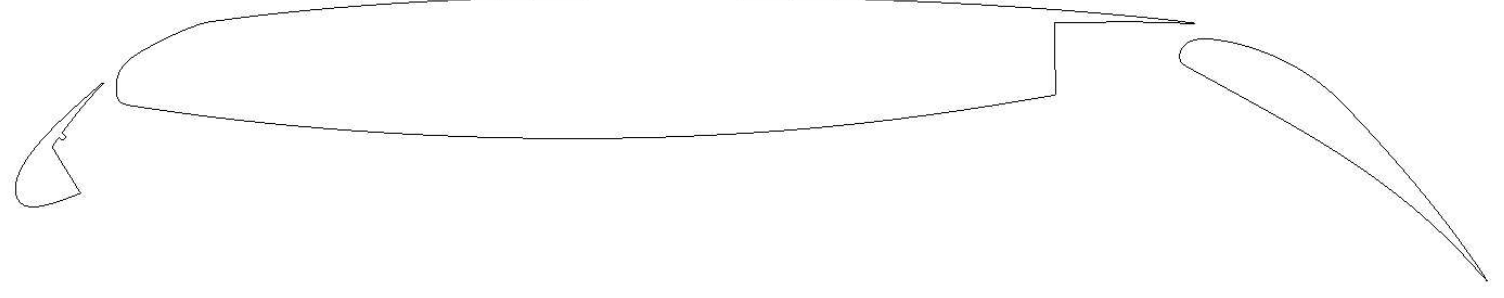

Fig.3. Two-dimensional profile of Boeing 777 high-lift system

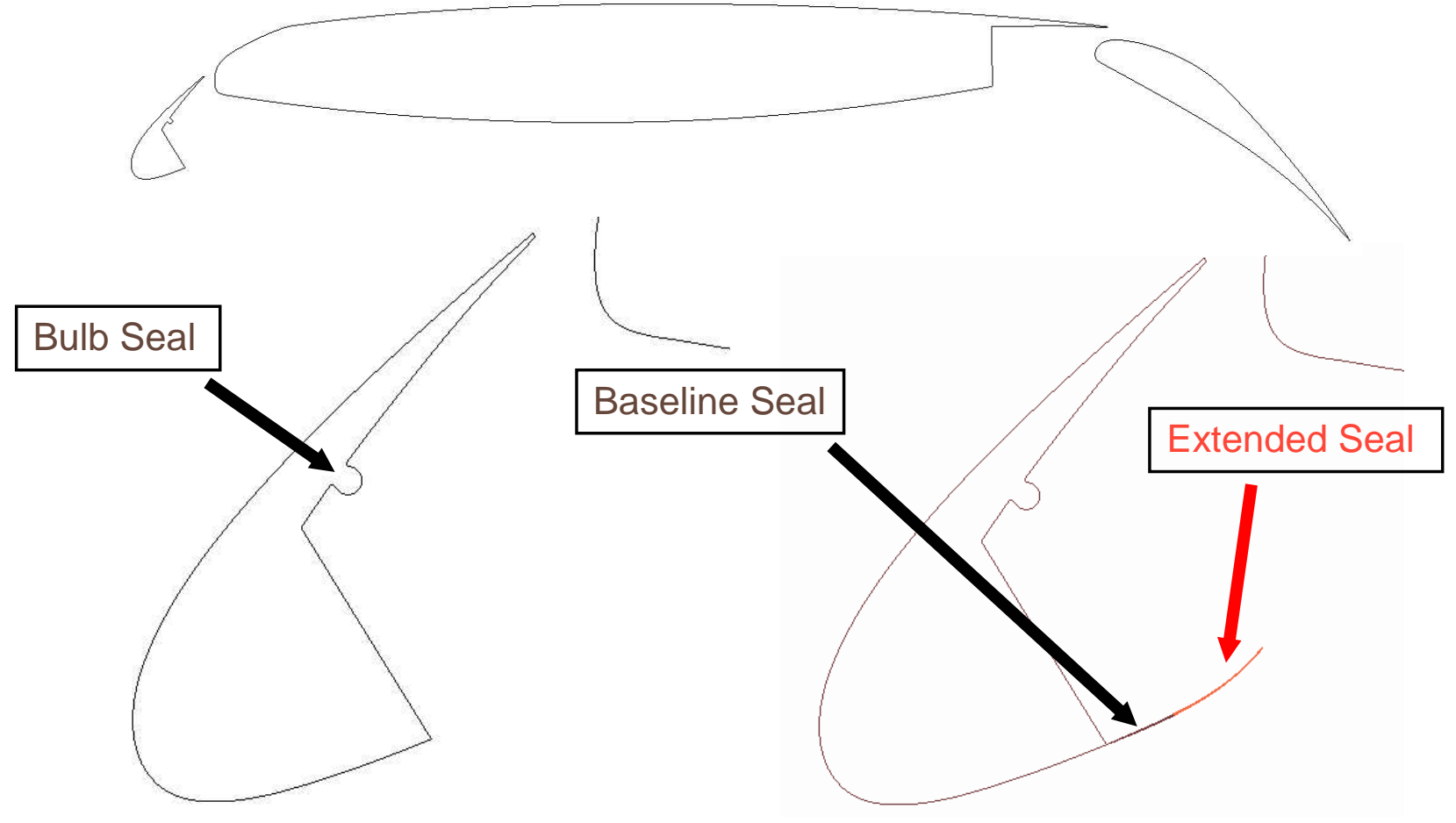

Fig.4. Added geometrical details showing bulb seal, baseline, and extended blade seals 


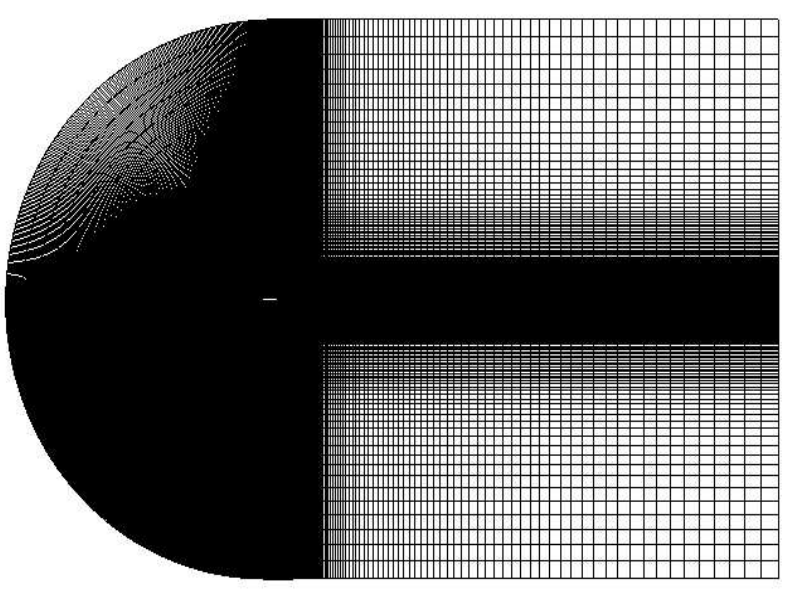

a) Full domain

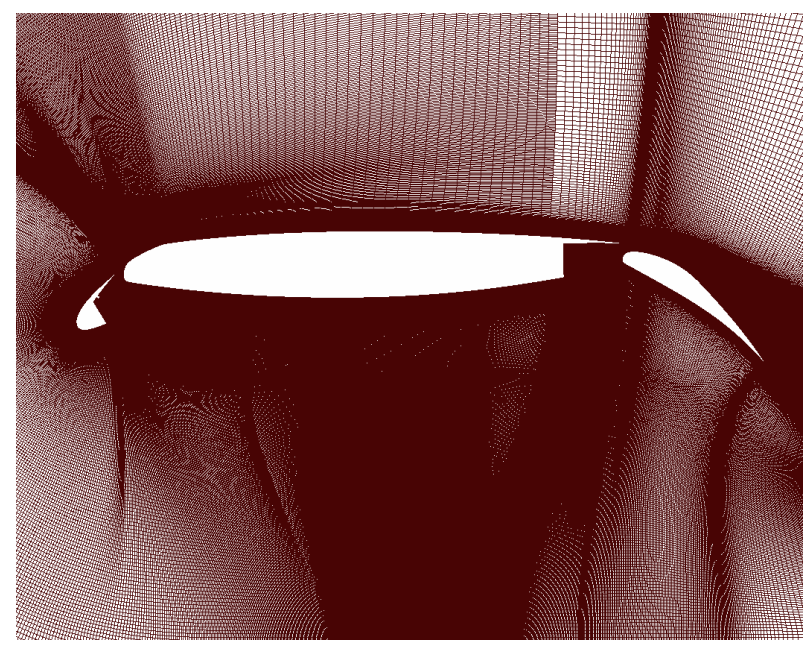

b) Near-field grid

Fig.5. Computational domain and grid distribution

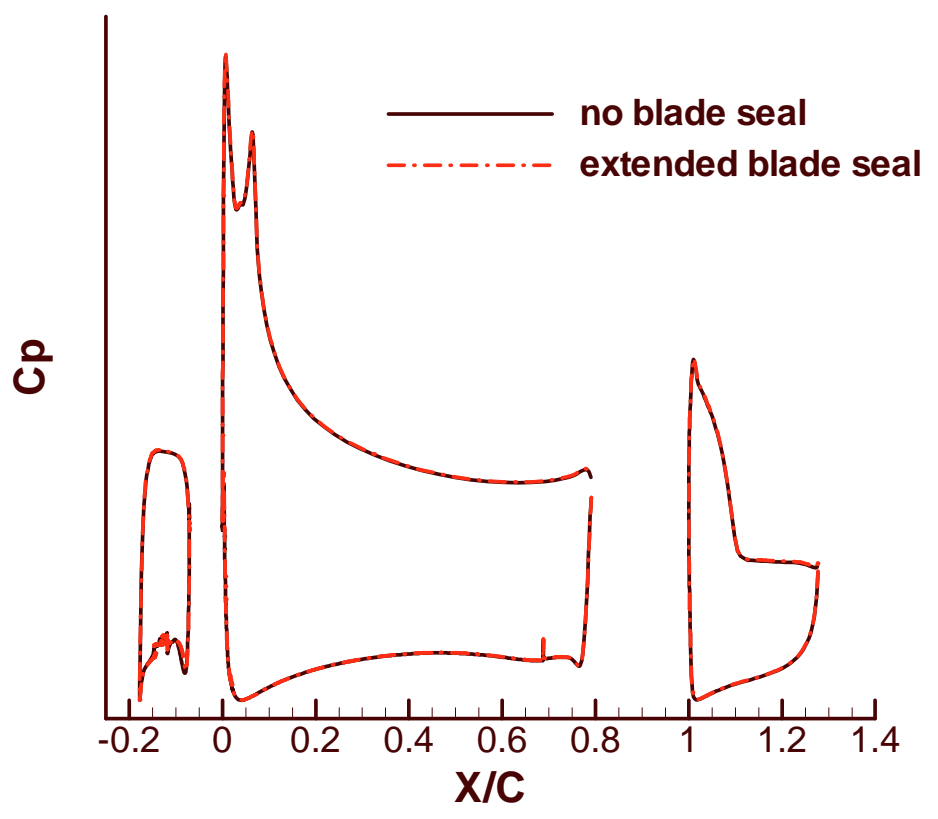

Fig.6. Surface pressure distribution 


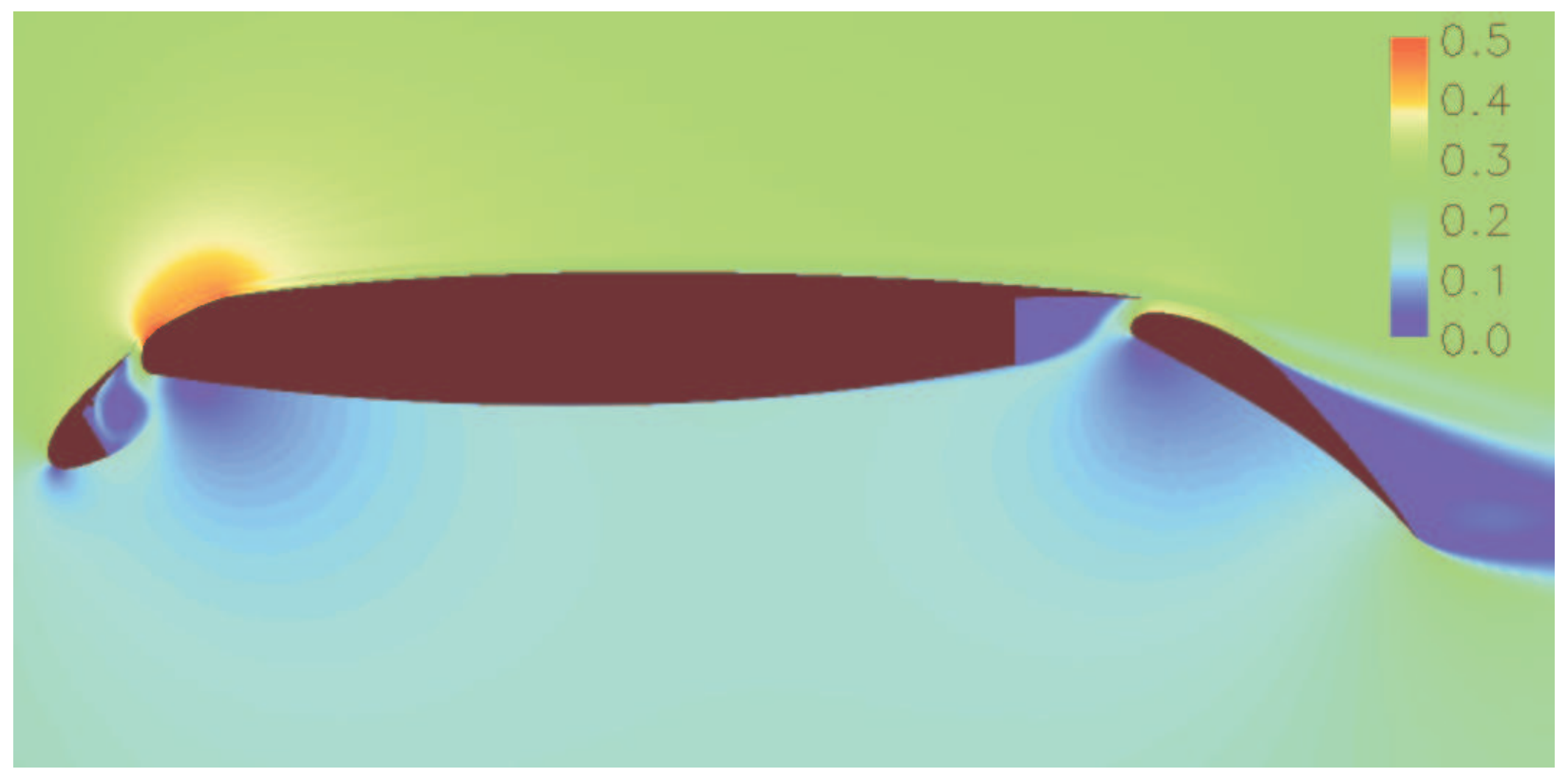

Fig.7. Averaged velocity-magnitude contours without blade seal

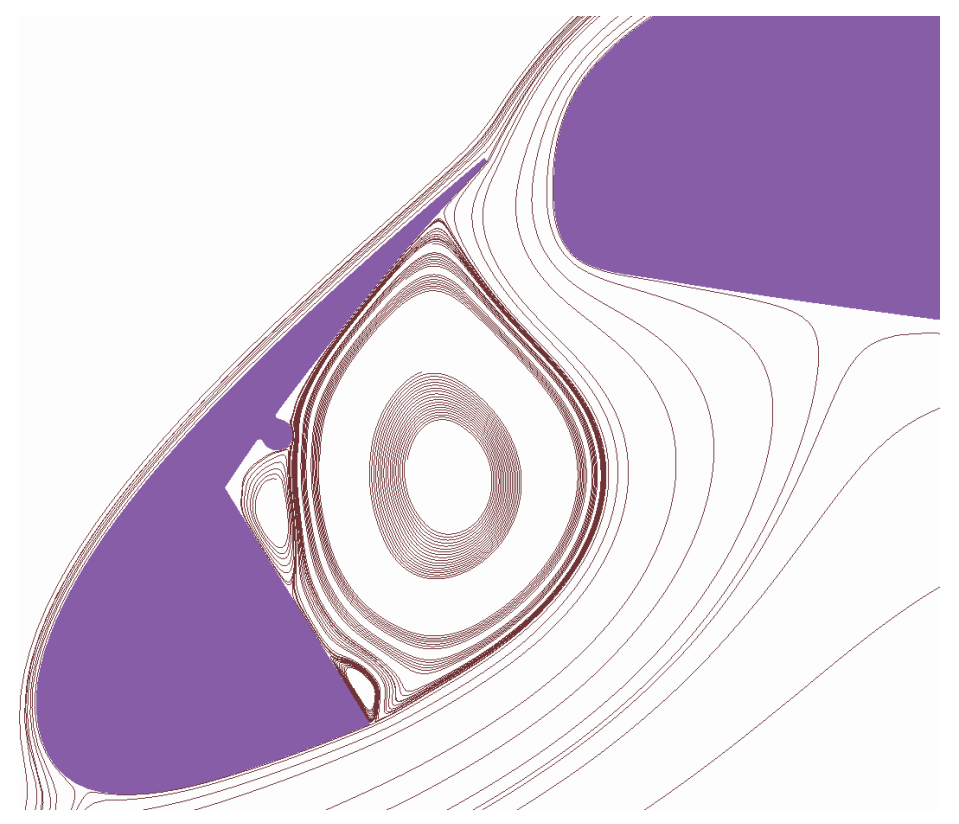

Fig.8. Average flow streamlines within cove region with no blade seal 


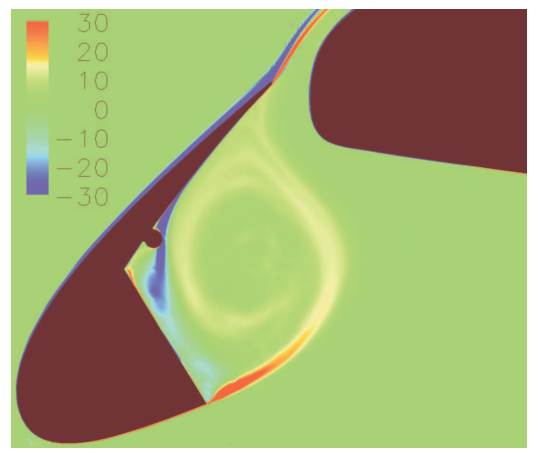

a) without blade seal

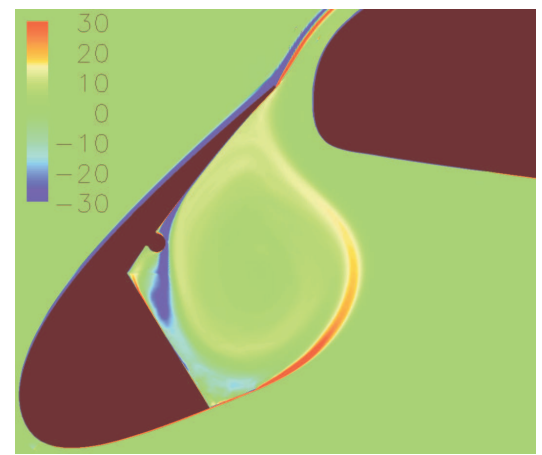

b) baseline blade seal

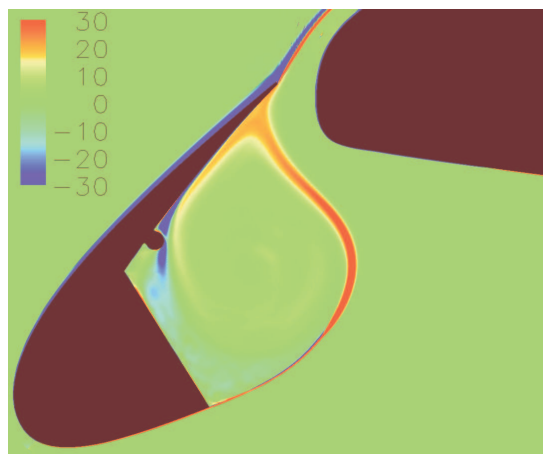

c) extended blade seal

Fig.9. Average spanwise vorticity field

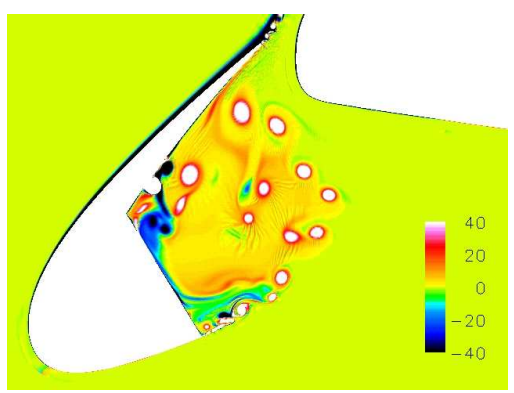

a) without blade seal

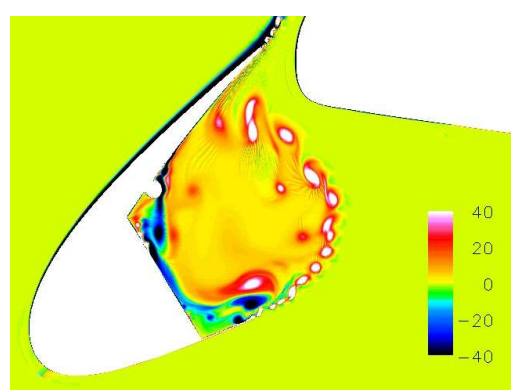

b) baseline blade seal

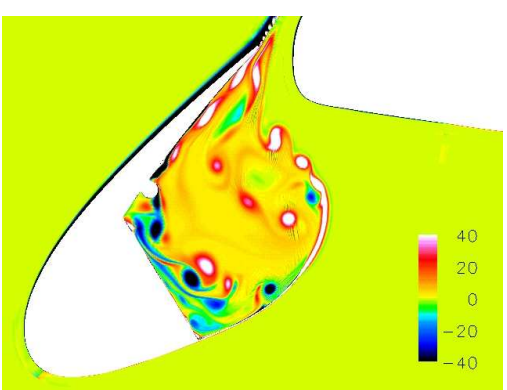

c) extended blade seal

Fig.10. Instantaneous spanwise vorticity field

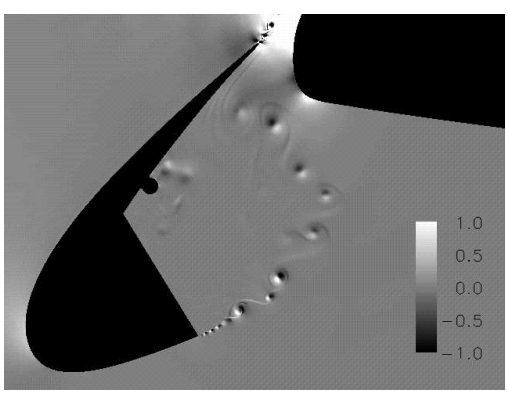

a) without blade seal

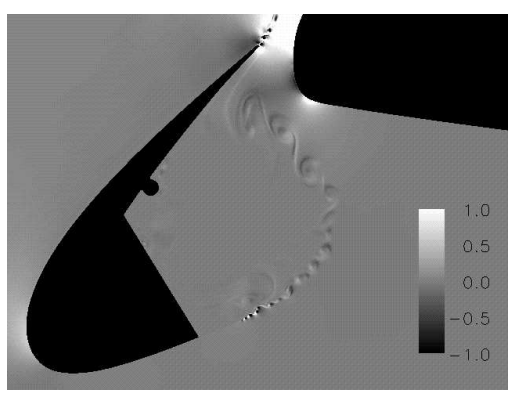

b) baseline blade seal

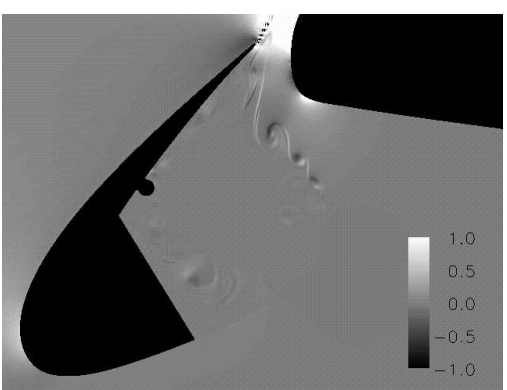

c) extended blade seal

Fig.11. Variation in rate of dilitation within slat cove region 


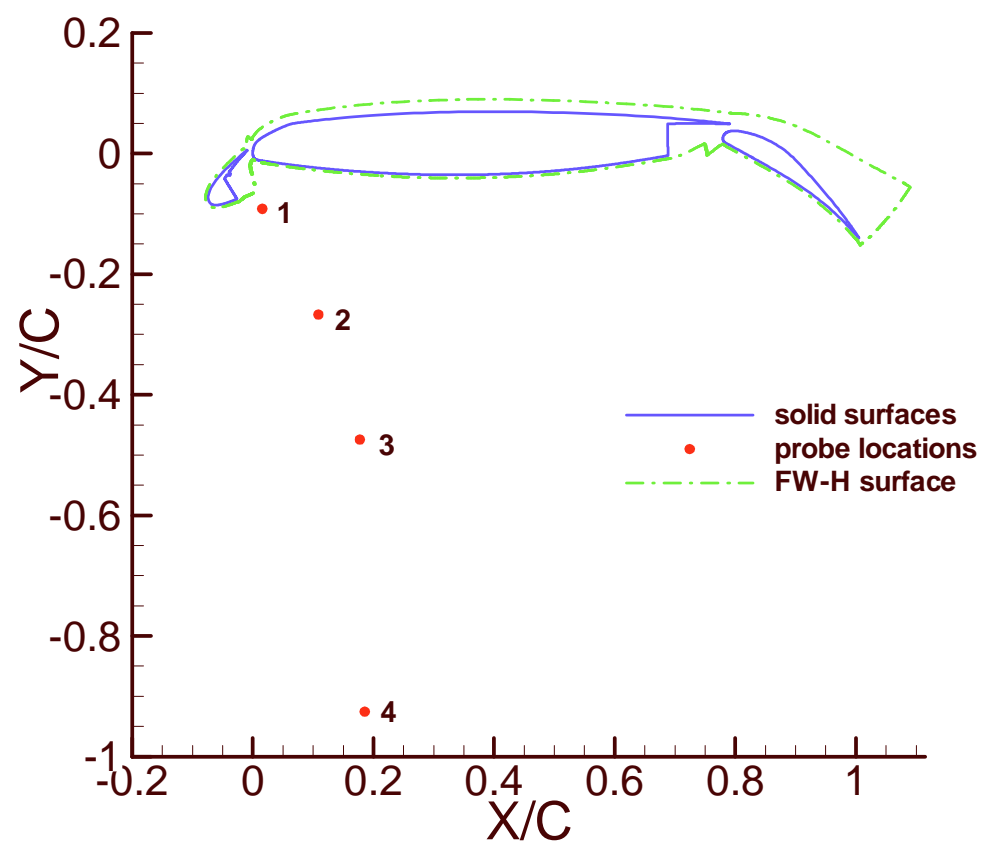

Fig.12. Solid and permeable surfaces and CFD probe locations 


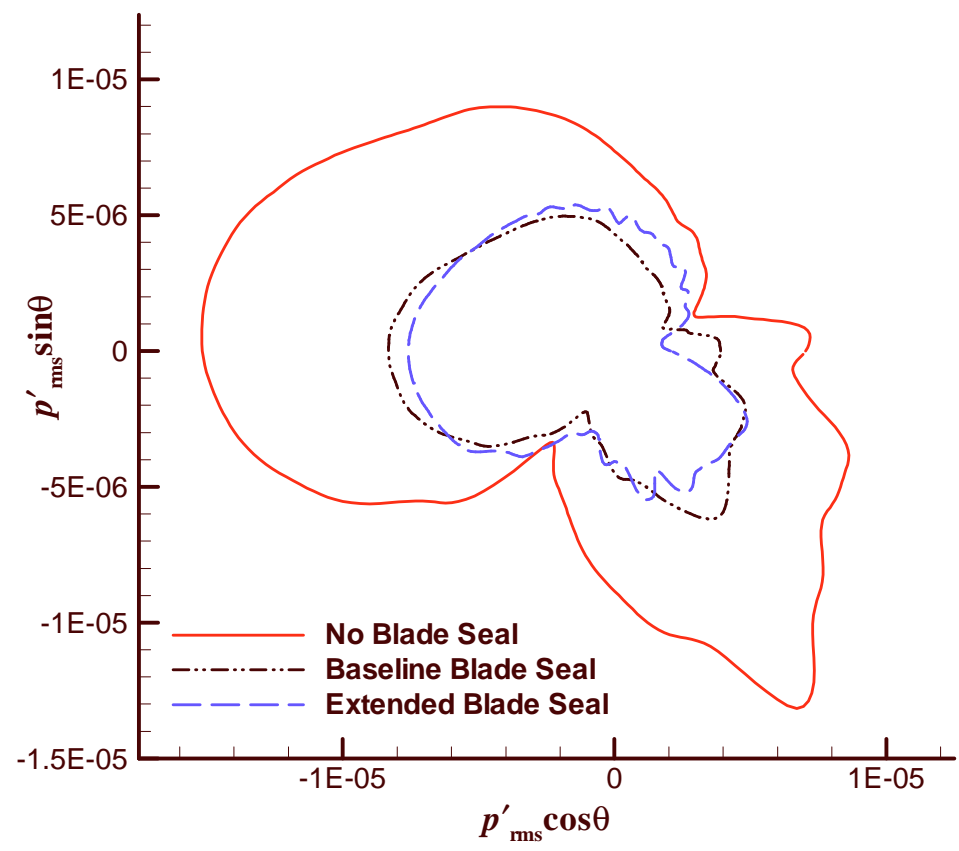

Fig.13. Slat directivity patterns

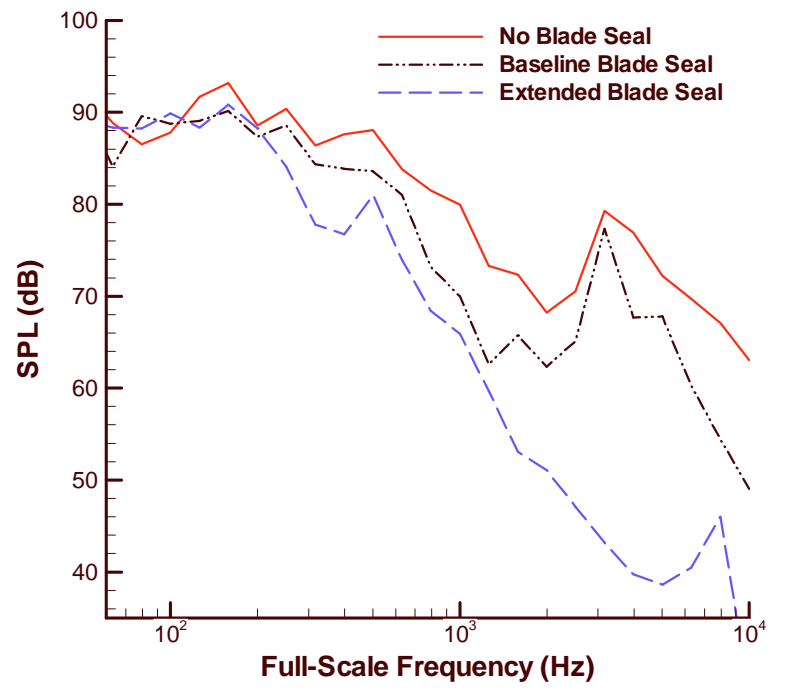

a) 270 degrees (overhead) direction

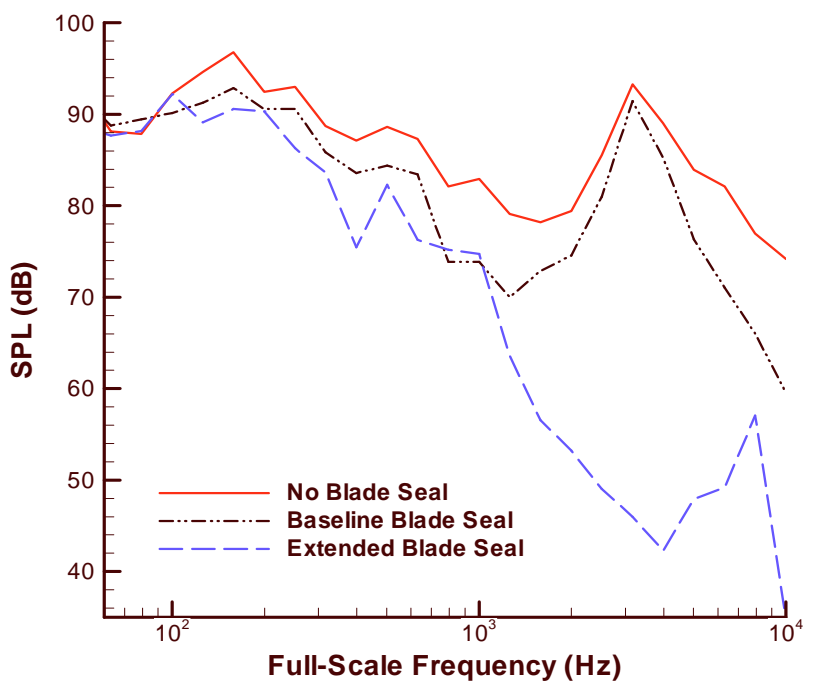

b) 298 degrees (max. amplitude) direction

Fig.14. Slat acoustic spectra 


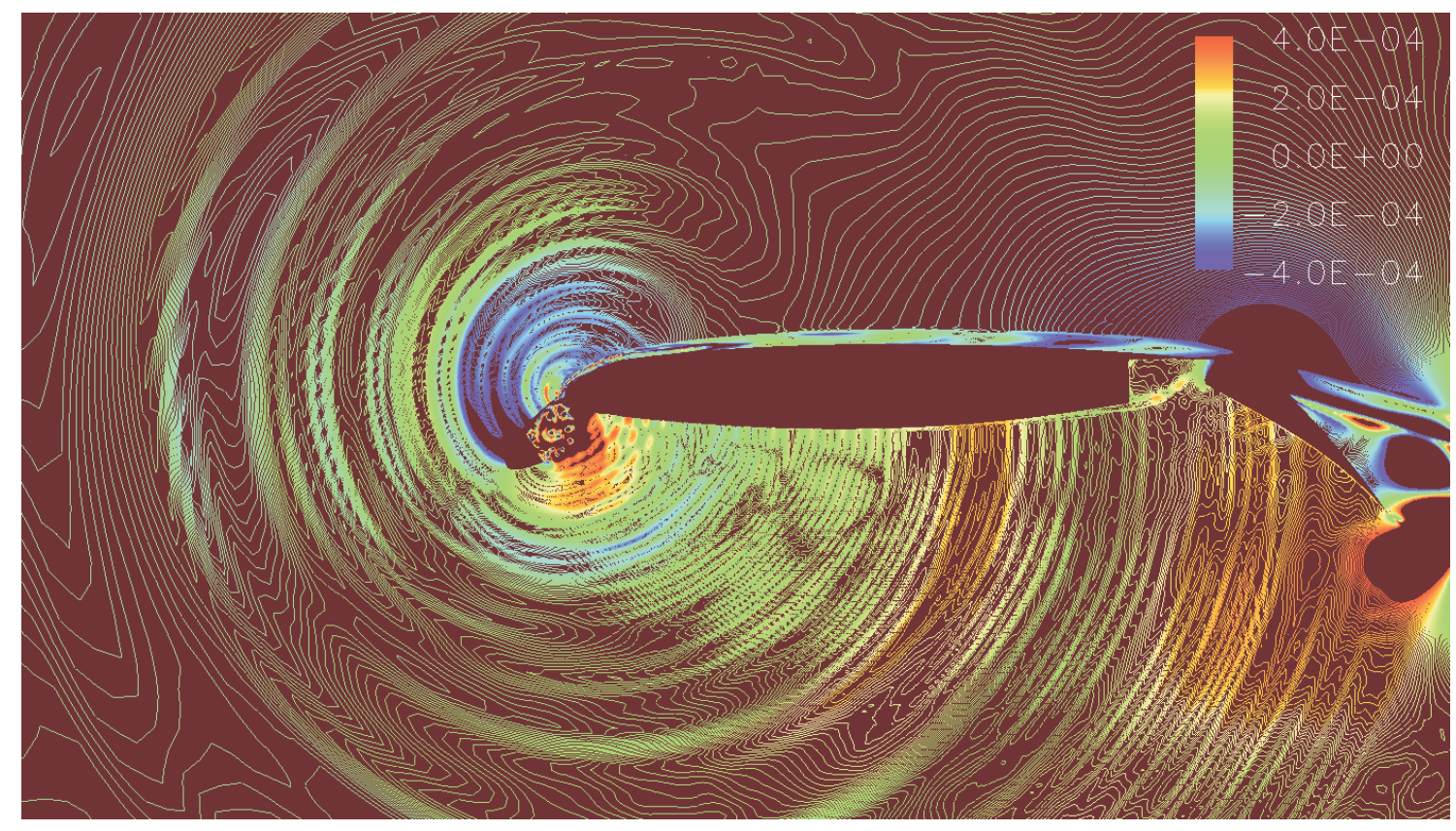

a) no blade seal

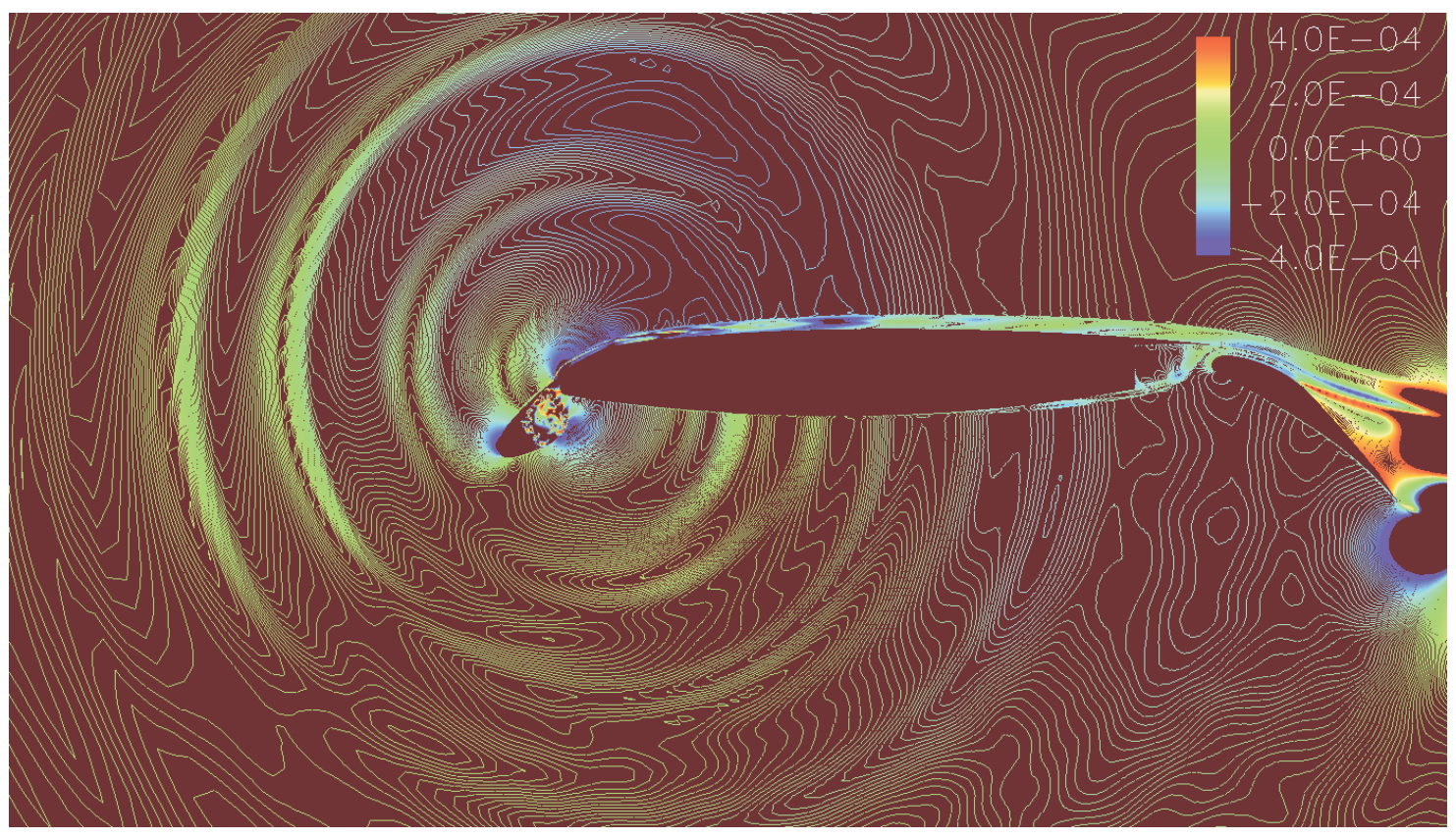

b) extended blade seal

Fig.15. Perturbation density field 


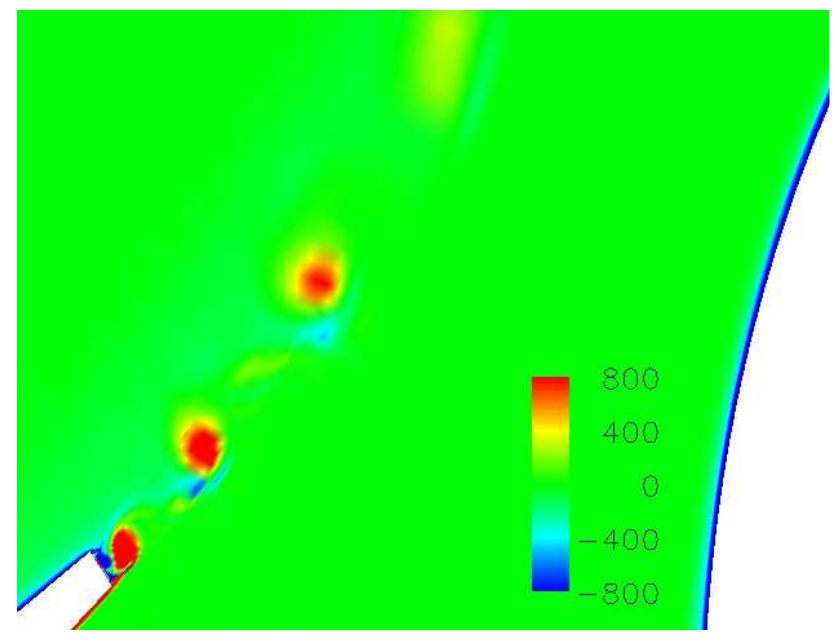

a) no blade seal

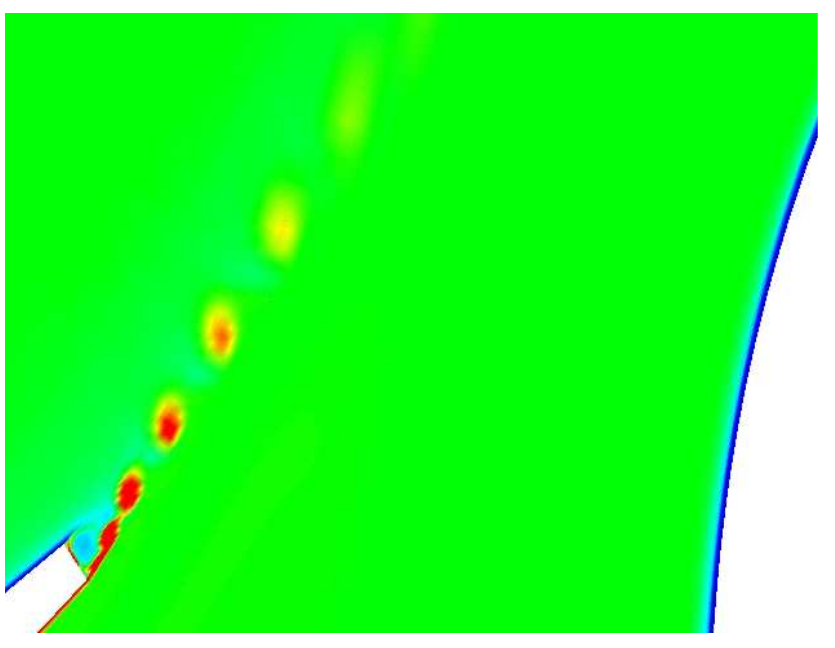

b) extended blade seal

Fig.16. Spanwise vorticity field at slat trailing edge

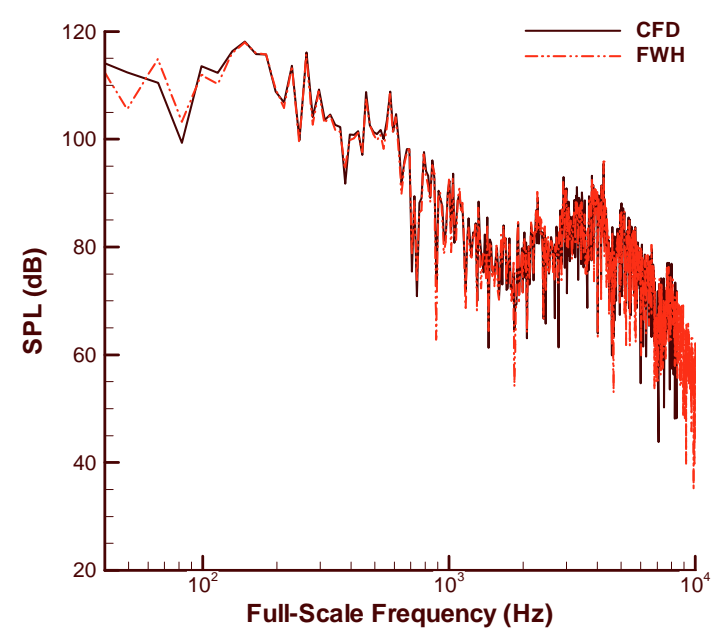

a) probe 1

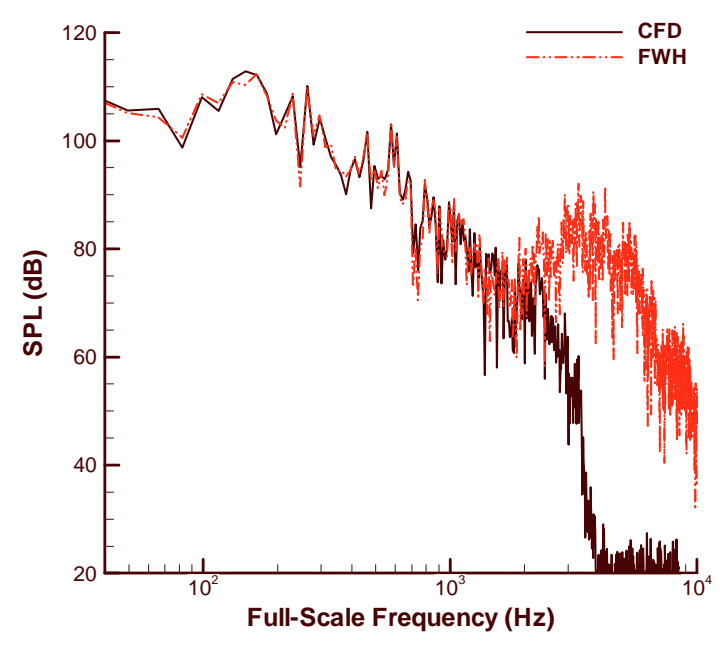

b) probe 2 


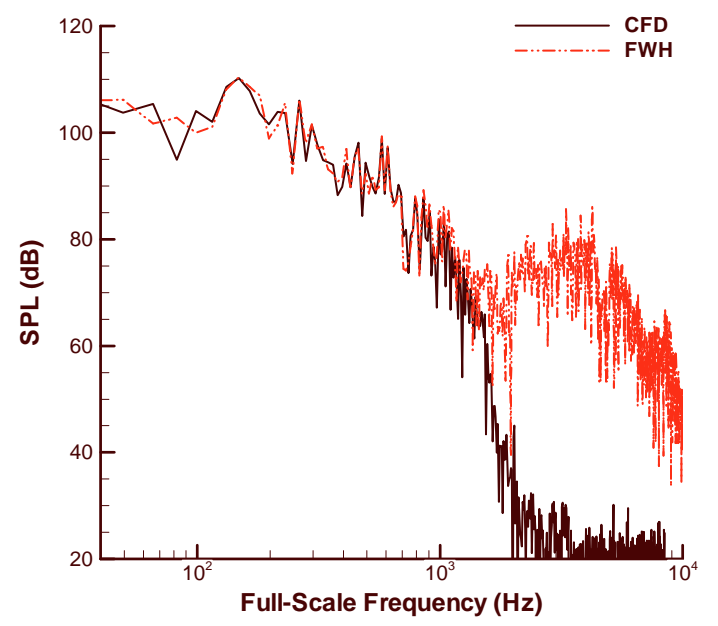

c) probe 3

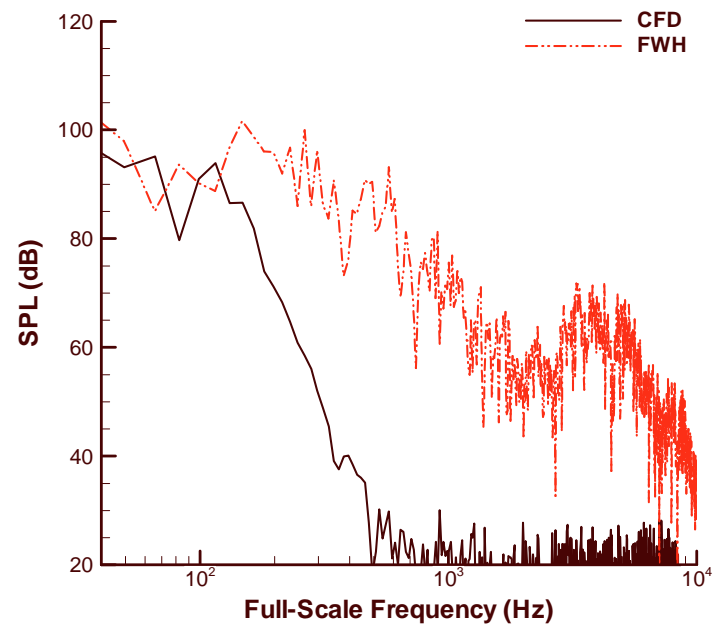

e) probe 5

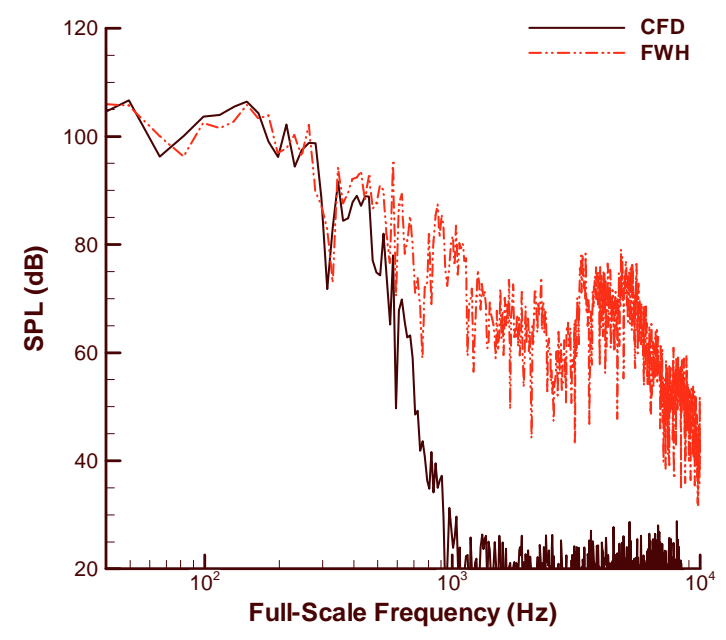

d) probe 4

Fig.17. Comparison between CFD results and FW-H calculations 